\title{
Retraction Note to: Deoxynivalenol-induced alterations in the redox status of HepG2 cells: identification of lipid hydroperoxides, the role of Nrf2-Keap1 signaling, and protective effects of zinc
}

\author{
Wageh Sobhy Darwish ${ }^{1,2} \cdot$ Zhen Chen $^{1} \cdot$ Yonghan $\mathrm{Li}^{1} \cdot$ Hui Tan $^{1} \cdot$ Hitoshi Chiba $^{3} \cdot$ Shu-Ping Hui ${ }^{1}$
}

Published online: 20 August 2021

○) Society for Mycotoxin (Research Gesellschaft für Mykotoxinforschung e.V.) and Springer-Verlag GmbH Germany, part of Springer Nature 2021

\section{Correction to: Retraction Note (2020) 36:287-299}

https://link.springer.com/article/10.1007\%2Fs12550-020-00392-x

The authors have retracted this article because after further experiments, they were unable to repeat the protective effect of $\mathrm{Zn}$ presented in Fig. 5. There were also some discrepancies in the statistical analysis with Tukey-Kramer test, used to create Fig. 5. In addition, the error bars represent standard error, and not standard deviation as stated in the figure legend. The data reported in this article are therefore unreliable.

All authors agree to this retraction.

Publisher's Note Springer Nature remains neutral with regard to jurisdictional claims in published maps and institutional affiliations.

The original article can be found online at https://link.springer. com/article/10.1007\%2Fs 12550-020-00392-x.

Shu-Ping Hui

keino@hs.hokudai.ac.jp

1 Laboratory for Advanced Lipid Analysis, Faculty of Health Sciences, Hokkaido University, Kita 12, Nishi 5, Sapporo, Japan

2 Food Control Department, Faculty of Veterinary Medicine, Zagazig University, Zagazig 44519, Egypt

3 Department of Nutrition, Sapporo University of Health Sciences, Nakanuma Nishi 4-2-1-15, Higashi Ku,

Sapporo 007-0894, Japan 